\title{
The long-term effect of renewable electricity on employment in the United Kingdom
}

\author{
Arvanitopoulos, $\mathbf{T}^{\mathrm{a}, \mathrm{b}}$, * \\ Agnolucci, P. \\ a Institute for Sustainable Resources, University College London, WC1H 0NN, United Kingdom. \\ b Tyndall Centre for Climate Change Research, University of East Anglia, Norwich NR4 7TJ, United \\ Kingdom.
}

\begin{abstract}
Assessment of the employment impact of renewable electricity technologies is generally implemented through either complex and data-intensive methods (such as Computable General Equilibrium models) or simplistic approaches, normally focused on specific energy generation technologies, such as employment factors. In contrast, this article proposes a transparent and easily reproducible econometric methodology based on the Vector Error Correction model that uses aggregated and widely available data. The model is applied to the power generation sector in the United Kingdom using annual data from 1990 onwards and provides evidence that the long-term employment impact of renewable technologies is much higher than the impact arising from deploying nuclear or natural gas technologies. The impulse response function analysis indicates that a permanent 1 Gigawatt-hours increase in annual electricity supply generated by renewable technologies creates 3.5 jobs in the long-term period. Finally, this study derives the implications of the findings in the context of decarbonisation scenarios for the power sector in the United Kingdom and assesses the extent to which decarbonisation pathways based on renewable rather than nuclear technologies contribute to stimulating employment in the generation sector.
\end{abstract}

\section{Highlights}

- Novel econometric methodology to estimate renewable energy net employment impact

- Method employs relatively aggregated data on UK national level

- $1 \mathrm{GWh}$ increase in annual renewable energy creates 3.5 long-term jobs

- Renewable energy generates about 6 times more jobs than nuclear

\footnotetext{
* Corresponding author at: Institute for Sustainable Resources, University College London, United Kingdom. Email address: t.arvanitopoulos@ucl.ac.uk (T. Arvanitopoulos).
} 
[Type here]

- Generation of 12.000 to 150.000 new jobs in the UK by 2030

Keywords: employment effect, electricity supply, renewable electricity, cointegration, impulse responses, decarbonization scenarios

JEL: $Q 43, J 23, L 94, C 32, C 51, C 53$

Word Count: 7996

List of abbreviations: Bioenergy with Carbon Capture Storage (BECCS), Carbon Capture Storage (CCS), Combined Cycle Gas Turbine (CCGT), Computable General Equilibrium (CGE), Contract for Difference (CfD), Dicky-Fuller Generalised Least Squares (DF-GLS), Digest of UK Energy Statistics (DUKES), European Union (EU), Gigawatt-hours (GWhs), Gross Value Added (GVA), Input-Output (IO), Impulse Response Function (IRF), International Renewable Energy Agency (IRENA), Lagrange Multiplier (LM), Likelihood Ratio (LR) Major Power Producers (MPPs), Megawatt (MW), Office for National Statistics (ONS), Organisation for Economic Co-Operation and Development (OECD), Other Generators (OGs), Office of Gas and Electricity Markets (Ofgem), Vector Autoregression (VAR), Vector Error Correction (VECM), United Kingdom (UK), UK Times model (UKTM), United States (US), Zivot Andrews (ZA). 


\section{Introduction}

Renewable technologies are an integral component in the mitigation of climate change [1]. The deployment of renewable energy technologies is sometimes considered a win-win scenario for both the environment and economic welfare, as they reduce carbon emissions and create employment in various sectors of the economy through direct and indirect effects. International Renewable Energy Agency [2] indicates that renewable energy can create a "considerable future potential" for net job creation, a suggestion generally backed up by most studies in the literature [3].

Since 2012, the deployment of renewable technologies has substantially increased, leading to the renewable energy sector globally employing 11 million people in 2018 [4]. The rapidly increasing maturity of renewable technologies along with the rising numbers of created jobs make it crucial that one investigates the employment effect of renewable electricity. Although there is a large number of papers doing so, these studies tend to focus on specific technologies, locations and plants and to discard the employment effect of fossil and nuclear generation technologies [5].

Based on extensive literature review, Cameron and Zwaan [5] conclude that the magnitude of the net employment effect varies significantly among countries, technologies and empirical methodologies with no clear consensus over the long-term sustainability of renewable jobs. This article helps bridge this lack of consensus by developing a novel methodology that assesses the long-term employment effect of different types of power generation technologies, including conventional thermal, from a macroeconomic perspective so that an estimate of the net job creation can be obtained by combining the results from this article to national decarbonisation scenarios. The approach of this study is a rigorous but simple and can be implemented by using relatively aggregated data. The methodology is applied to renewable electricity produced in the United Kingdom (UK) as a case study. Employment in the UK energy generation sector is modelled as a function of a) economic activity and b) the level of electricity generated by conventional thermal (oil and coal), combined cycle gas turbine (CCGT), nuclear and renewable technologies. The proposed econometric methodology has relatively low data requirements based on a Vector Error Correction (VECM) model. This means that it can be estimated on national data for employment and economic activity in the power sector (regardless of the technology being used) and the amount of electricity produced by different power generating options. Therefore, the main advantage of this approach is that it avoids the data burden typical of Input-Output (IO), Computable General Equilibrium (CGE) and macroeconometrics sectorial models [5], with the additional advantage that the relationships estimated in this model are transparent, contrary to other approaches, such as CGE models, using several elasticity parameters, not always made explicit in the studies. The proposed approach is implemented in the case of the UK electricity generation market as 
[Type here]

it is highly competitive [6] with diverse energy mix, a significant proportion of which has been increasingly being generated by renewable technologies.

By quantifying the employment impact of a number of energy technologies, the proposed methodology can be applied on the back of the output of energy system models which produce deployment scenarios of electricity generation technologies to achieve a certain level of decarbonisation. This implies the possibility of computing the net effect from the deployment of renewable technologies on employment in renewable and fossil-fuel based plants, respectively. In addition, the proposed methodology can be easily replicated across countries therefore increasing empirical evidence base while taking into account the context of a particular country, such as industrial and labour policy, technologies being used in power generation and labour productivity. All variables used are observed at the annual frequency, although one could use quarterly or monthly data, in those cases where they are available. The ability to use annual observations instead of more granular ones increases the applicability of the method which uses data which are readily available for the member countries of the Organisation for Economic CoOperation and Development (OECD). Thus, this study is of interest to both UK policymakers and government officials while replication of this study in other countries would be of similar interest to policymakers in the country of interest.

This paper is structured as follows. Section 2 reviews the recent literature on employment and renewable electricity. Section 3 analyses the UK electricity supply market. Section 4 explains the methodological approach while Section 5 provides details on the data used in. Results are presented in section 6 and discussion on policy relevance can be found in Section 7. Section 8 concludes.

\section{Literature review}

Jobs created by renewable technologies can be distinguished in (i) direct, (ii) indirect and (iii) induced [2]. Direct jobs are created by the sector's core activities, indirect are those related to the supply chain of the energy sector (e.g. firms providing raw materials, regulatory bodies, banks, etc.) while induced jobs are generated by an increase in the aggregate demand stimulated by the renewable sector [7]. Gross employment comprises the overall employment created by an increase in the generation of renewable energy while net employment takes into account the missed employment which would have been generated in counterfactuals, i.e. the employment which would have been generated by the plants which would have been built in the place of renewables.

The existing literature on the employment effect of renewable technologies - part of a wider branch assessing the employment effect of sustainable development policies [8] - comprises a large number of studies employing various techniques and methodological approaches. Cameron and Zwaan [5] identify 70 publications since the beginning of the last decade, but only a small subset can be considered as 
[Type here]

presenting original research, as the literature is affected by a high degree of recursive referencing, so that many studies merely re-use or recycle findings from earlier publications [5]. Existing publications grouped into studies 1) producing forecast or simulations based on theoretical models, external estimates and conversion of values from other papers e.g. [9]; 2) performing some form of literature review e.g. [10]; and 3) analysing historical employment data to empirically estimate gross employment effects. The latter group of studies can be further divided in three subgroups based on the type of empirical methodology, i.e. IO, CGE and employment factors. IO models estimate interdependencies between different economic sectors and employment effects of renewable energy, especially with regard to indirect and induced jobs such as $[11,12,13,14,15,16]$. CGE models, such as $[17,18,19]$, are macroeconomics models that account for the economy-wide ramifications of renewable energy and provide estimates of the employment effect for induced jobs across the economy. Finally, employment factors are ratios of a specific type of employment to the level/capacity of electricity generated by a specific type of renewable technology (e.g. the direct employment factor for manufacturing and installations for wind energy is measured as job/MW) [20, 21, 22, 23, 24] and mostly focus on direct job creation. By performing a meta-analysis on studies investigating the employment effect of renewables, [25] find that the magnitude of net employment effect is mainly driven by the implemented methodology. More specifically, [25] find that studies based on IO and CGE with induced effects tend to be less favourable to net job creation while policy reports tend to be more supportive of net job creation.

Evaluating empirical results found in the literature, [5] note that the employment impact varies across renewable technologies. ${ }^{1}$ The German labour market has been in the forefront of attention as a series of studies indicates the positive effect of renewables on creating job opportunities [26, 27, 28, 29]. Studies investigating the employment effect of solar industry development focus especially on Mediterranean countries [30, 31, 32, 33, 34, 35, 36, 37] and Middle East [38]. Wind energy is expected to stimulate job creation in the European Union (EU) [24, 39] and the United States (US) [40, 41], an argument that is further supported for countries such as Brazil [42,43], Greece [30, 31] and Spain [44, 33, 34]. Investing in renewables is expected to create job opportunities also in East African economies [45]. However, in the case of Texas, [46] found no statistically significant impact of wind electricity on employment, revealing that the type of landscape, ownership and local participation are all crucial factors to maximise local employment effect [47]. Similarly, [48] find small sectoral employment effects of Clean Development Mechanisms projects across Brazilian municipalities. On the other hand, [49] that use a macro-economic sectorial model for Germany find that renewable technologies had positive net employment effect. Although this net effect is small if labour markets are not flexible, it can become considerably high if the newly created jobs are filled with workers that have been recently

\footnotetext{
${ }^{1}$ For example, solar panels can create several times more jobs than onshore wind.
} 
[Type here]

unemployed. The importance of retraining workers in the transition from coal to renewable electricity is discussed in [50]. Cost-competitive wind electricity was found to produce initially low but rising benefits in terms of welfare and GDP in the case of the US economy [51]. On a wider scale, doubling the share of renewables in world electricity production was found to increase direct and indirect employment in the sector to 24.4 million by 2030 , with most renewable jobs coming from fuel supply (bioenergy feedstocks), installations and equipment manufacturing [52]. Concerning the UK job market, [21] investigate the potential employment effect in Wales by regional deployment of tidal and wave-based renewable technologies while [53] valuate the expected net employment impact of rising production and use of biomass crops in UK bioenergy plants.

From an economic theory perspective, increasing renewable electricity tends to imply higher unemployment rate [54] mainly through increases in the labour tax required to fund renewable electricity schemes. [55] confirms that labour market rigidities and existing unemployment provide some scope for a double dividend, but in practice these are likely to be limited, like in the case of the employment effects of the renewable energy expansion in Germany computed in [55]. Using a panel dataset of 80 countries, [56] find positive impact of renewable energy consumption on unemployment in European Union and Africa while negative in Asia and Latin American countries. [57] describe the existence of three economic channels for job creation, so that a shift in investment towards renewables increases employment if it targets sectors with a higher share of labour compensation out of value added, lower wages or lower import rates. The authors found positive employment impacts arising from weatherproofing and solar panels, a result that is robust across models used in the study. [5] argue that the maturity of production techniques, economies of scale and automatisation of industrial processes can lead to reduction of employment in the longrun. A small number of studies quantifying the effect of economies of scale on long-term employment $[58,59,60]$ indicate high levels of reduction in employment rates, although this subject needs to be further investigated [5].

\section{Electricity supply and the UK policy framework}

The UK electricity market was restructured in 1990 to allow private investors enter the previously nationalised market through a competitive bidding system that resulted in lower energy prices [61]. Companies generating electricity are classified in Major Power Producers (MPPs) and Other Generators (OGs). MPPs are firms whose "primary purpose is the generation of electricity" [61], while OGs are companies that "produce electricity as part of the manufacturing or other commercial activities, but whose main business is not electricity generation" [12]. OGs generate electricity mostly to satisfy their industrial energy needs while surplus is normally exported to the grid. ${ }^{2}$ Digest of UK Energy Statistics

\footnotetext{
${ }^{2}$ Although the long-term relationship between electricity supply generated by OGs and employment has also been investigated, findings do not support this argument. Thus, the present study focuses solely on MPPs whose "primary purpose is the generation of electricity" [61].
} 
[Type here]

(DUKES) [61] divides electricity supply into conventional thermal, CCGT, nuclear and renewable electricity supply. Conventional thermal supply includes electricity generated by turbines burning coal and oil, while CCGT is a technology that uses natural gas (or gas oil to a small extent) to produce electricity at higher efficiencies than conventional thermal technologies. Nuclear electricity is generated by nuclear power plants all of which are classified as MPPs while, according to the Directive 2009/28/EC, renewable electricity is generated by renewables non-fossil sources such as hydro, wind farms, and solar farms [61]. ${ }^{3}$

Conventional thermal technologies generated $77 \%$ of total electricity supply in 1990 - the year that CCGT plants introduced in the UK - but by 1999 a $42 \%$ reduction took place (see Figure 1) mostly due to coal being replaced by gas burnt in CCGTs, the so-called "dash for gas" $[62,63]$ which implied a 113,000 Gigawatt-hours (GWh) increase in CCGT generation in the same time period ${ }^{4}$. From 2000 to 2013, conventional thermal and CCGT power stations supplied roughly similar levels of electricity although after the 2008 economic crisis there has been increased instability in the two series. Finally, from 2013 to 2016 conventional electricity decreased to become responsible only for $15 \%$ of electricity supply in $2016^{5}$ while CCGT electricity has increased by $20 \%$ covering in 2016 almost $50 \%$ of total UK electricity supply. From 2016 to 2018, conventional thermal, CCGT and nuclear electricity have experienced gradually declining trends.

\footnotetext{
${ }^{3}$ There has been a major amendment in the MPPs definition in 2008 so that major wind farm companies could change classification from OGs to MPPs while the definition was further amended in 2015 to also include large scale solar farm companies which before 2015 were identified as OGs.

${ }^{4}$ See also the symmetric behaviour of the time series for conventional thermal and CCGT power stations between 1990 and 2000 in Figure 1(a).

${ }^{5}$ This reduction is mainly because in 2015 the carbon price floor has doubled from $9 £$ to $18 £$ per tonne of $\mathrm{CO}_{2}$ [61].
} 
[Type here]

\section{GWhs}

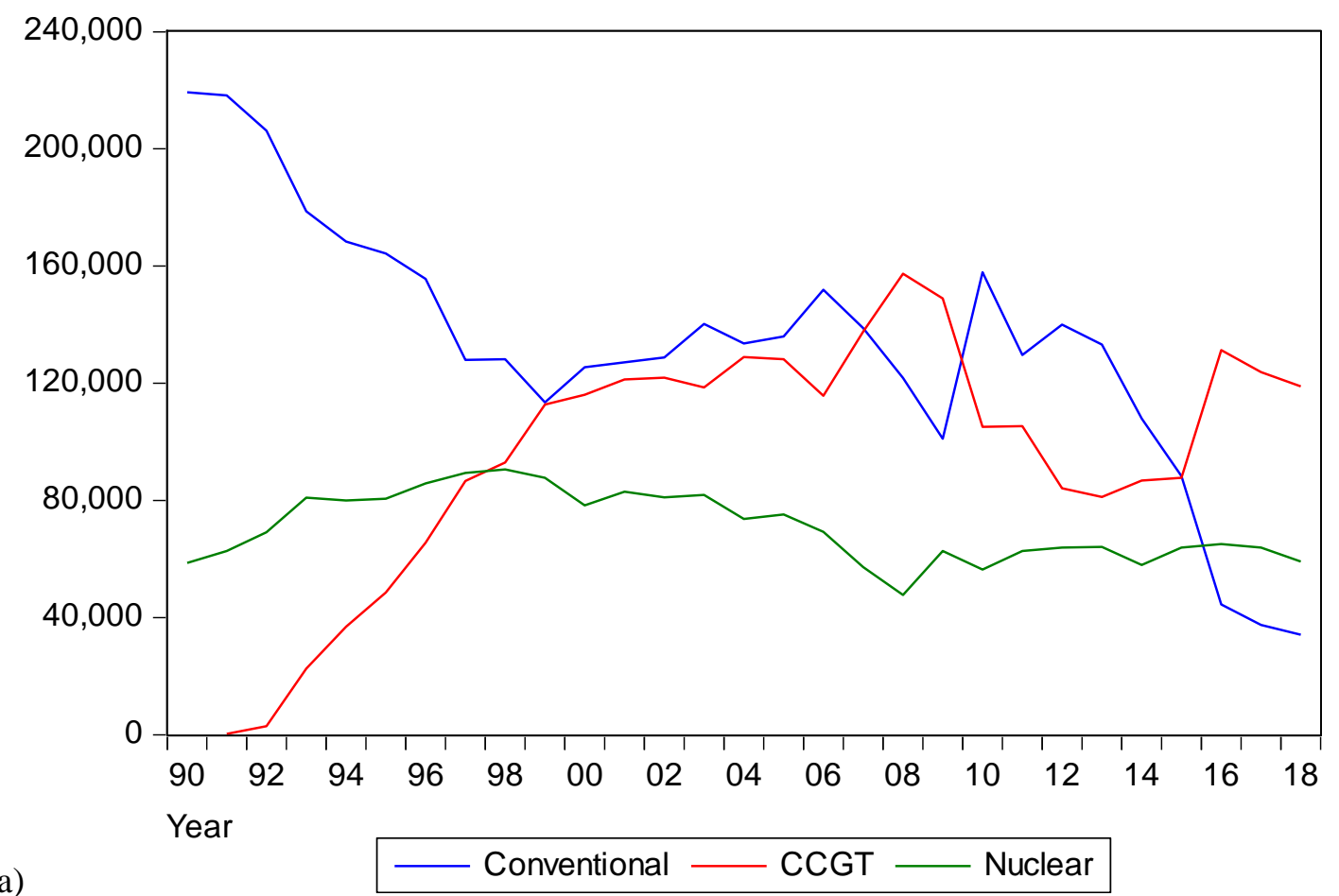

(a)

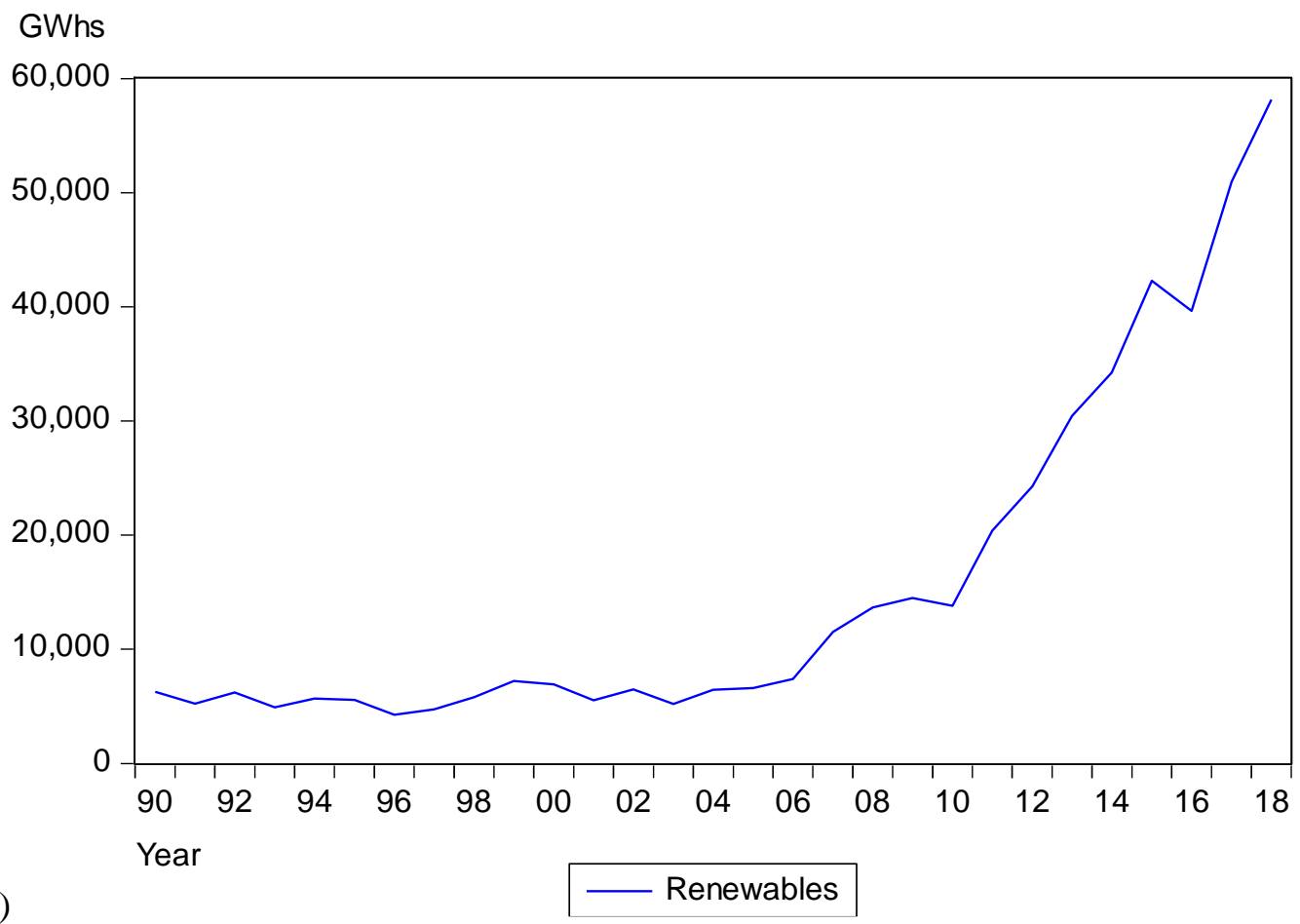

Figure 1. Total annual electricity supplied (GWhs) by Major Power Producers (MPPs) per type of electricity generation technology used in power generation process 
[Type here]

Nuclear power stations have generated on average $23 \%$ of total UK electricity supply since 1991, with the lowest level of electricity supply being 14\% in 2008 and the highest being 29\% in 1997 and $1998^{6}$. Since 1998 several nuclear plants have been gradually decommissioned so that only eight nuclear plants were left in operation in 2017 [61] out of the sixteen that were in operation in 1995, explaining the overall reduction in nuclear electricity. Decline in nuclear electricity took place in correspondence of a rebound of conventional electricity up to 2007.

Contribution from renewable technologies has steadily increased since the late 2000s. In 2007 the EU Renewable Energy Directive (RED) set as target by 2020 the production of $20 \%$ of electricity supply by renewable resources while in the UK the target was set in 2009 at the level of $15 \%$ of the total energy [61]. The Energy Act 2013 established the Contracts for Difference (CfD) policy framework through which the UK government ensures secure, affordable and clean electricity supplies [6]. More specifically, CfD policy incentivises business stakeholders to invest in renewable energy projects by providing them with sufficient credit to cover upfront capital costs. It further provides renewable energy generators with a fixed price and tops up the wholesale price when it is lower than the agreed price [6]. As a result, renewable electricity has steadily increased up to 2018 (Figure 1(b)) with a small reduction in 2016 attributed to unfavourable weather conditions for wind [61]. Increase in electricity from renewable plants has occurred in presence of shrinking production from conventional thermal plants from 2010 onwards.

To sum up, production from conventional thermal plants has decreased since the restructuring of the power market in the 1990s so that it is reasonable to expect substitution between electricity supply generated by conventional thermal plants and other technologies. One should expect the existence of substitution between conventional thermal and CCGT, as discussed at length above. Nuclear technologies have played a central role in the UK electricity market with their declining output in the 1990s initially filled by increasing production from conventional thermal plants in a way that substitution should exist between electricity generated by conventional thermal and nuclear technologies. Only nuclear and renewables can deliver $\mathrm{CO}_{2}$-free electricity required to meet UK's $\mathrm{CO}_{2}$ targets. Hence, it is reasonable to expect substitution between nuclear and renewable electricity, as a certain level $\mathrm{CO}_{2}$ target can be reached by either increasing electricity from renewable or nuclear, given a certain deployment of electricity from CCGT and conventional thermal plants.

\footnotetext{
${ }^{6}$ The peak in 1997 and 1998 reflects the fact that Sizewell B has been the latest nuclear power plant to enter commercial operation in 1995.
} 
[Type here]

\section{Methodological approach}

The methodological approach of this paper comprises two steps. The first step (Section 4.1) establishes a theoretical framework for the reduced form model that explains how the future number of jobs in the representative power producing firm is determined by the firm's expectation of future electricity demand. The second step (Section 4.2) involves the empirical implementation of the theoretical model with the use of econometric modelling and can be further divided in: (a) unit root testing, (b) cointegration testing, (c) VECM modelling, (d) impulse response function (IRF) analysis.

One can use as a starting point the consideration, supported by DUKES [61, p.113], that the UK electricity system is driven by demand which in other words means that UK electricity supply is competitive in nature. Indeed, the wholesale electricity market in the UK is moderately concentrated while according to the Office of Gas and Electricity Markets (Ofgem) [6] the degree of market concentration $^{7}$ has significantly decreased during the last decade. Overall, the installed capacity has increased during the last decade mainly due to policies such as the CfD which support the investment in renewable technologies [6]. This allows the related labour market to be fully flexible and competitive enough to efficiently accommodate changes in the energy mix of electricity generation ${ }^{8}$.

\subsection{A theoretical framework}

A representative firm in the electricity generation market chooses labour inputs $\left(L_{t}\right)$ at time $t$ based on its expectations $\left(E_{t-1}\right)$ at time $t-1$, using all available information $\left(I_{t-1}\right)$ at time $t$ - 1 , of the electricity it will supply $\left(e_{t}\right)$ at time $t$. This can be expressed as:

$$
L_{t}=f\left(E_{t-1}\left[e_{t} \mid I_{t-1}\right]\right)
$$

The firm's expectation in relation to electricity supply at time $t$ can be further distinguished into the sum of expectation $E_{t-1}\left[\operatorname{con}_{t} \mid I_{t-1}\right]$ for conventional thermal, $E_{t-1}\left[\operatorname{ccgt}_{t} \mid I_{t-1}\right]$ for CCGT, $E_{t-1}\left[\right.$ nuc $\left._{t} \mid I_{t-1}\right]$ for nuclear and $E_{t-1}\left[\operatorname{ren}_{t} \mid I_{t-1}\right]$ for renewable electricity at time $t-1$ so that:

$$
\begin{gathered}
E_{t-1}\left[e_{t} \mid I_{t-1}\right]=E_{t-1}\left[\operatorname{con}_{t} \mid I_{t-1}\right]+E_{t-1}\left[\operatorname{ccgt}_{t} \mid I_{t-1}\right]+E_{t-1}\left[\operatorname{ruc}_{t} \mid I_{t-1}\right]+ \\
E_{t-1}\left[\operatorname{ren}_{t} \mid I_{t-1}\right] .
\end{gathered}
$$

The representative firm forms its expectation about time $t$ by taking into account demand for electricity observed at time $t-1$ and in all past years, with diminishing weights attributed to the past years used to form the expectation. Thus, an increase in electricity demand at time $t-1-$ and by extent an equal

\footnotetext{
${ }^{7}$ The degree of market concentration is measured by Ofgem with the use of the Herfindahl-Hirschman index.

${ }^{8}$ Employment depends both on installed and operating capacity of distinct renewable technologies. Since this study focuses on the macro level of the economy and uses aggregated data, it seems more sensible to look at the generation. It would be interesting in the future to use installed capacity data instead.
} 
[Type here]

increase in electricity supply - implies an increase in the representative firm's expectations of electricity demand in time $t$ with expectations adjusted by a parameter $\beta$ which takes values between 0 and 1 . The parameter takes the role of an "error-adjustment" term reflecting the deviations between expectation at $t-2$ of electricity consumption at $t-1, E_{t-2}\left[e_{t-1} \mid I_{t-2}\right]$, and actual consumption of electricity at $t-1, e_{t-1}$ :

$$
E_{t-1}\left[e_{t} \mid I_{t-1}\right]=E_{t-2}\left[e_{t-1} \mid I_{t-2}\right]+\beta\left(e_{t-1}-E_{t-2}\left[e_{t-1} \mid I_{t-2}\right]\right)
$$

As under the assumption of adaptive expectations, the expectation of a future variable is based on all past observations, equation (3) can iteratively be expressed as follows:

$$
E_{t-1}\left[e_{t} \mid I_{t-1}\right]=\beta\left(\sum_{j=0}^{\infty}\left(1-\beta_{1}\right)^{j} e_{j}\right)
$$

for years $j$ in the past. It is true that distinct technologies within the same energy generation category (for example solar, wind, etc.) have different employment effect and that even the magnitude of the employment effect from a given technology varies across the stages of the technological development of the technology. One of the advantages of the approach of this study is that it estimates the average employment effect without having to focus on the characteristics of individual generation technologies. As a positive employment effect in time $t$ might not only be the outcome of higher electricity consumption but also of higher economic activity, one has to control for Gross Value Added (GVA) in the electricity generation sector.

\subsection{Econometric modelling}

The first step of the empirical modelling consists in testing the stationarity of the variables using the Dicky-Fuller Generalised Least Squares (DF-GLS) test. [64], choice motivated by high size-adjusted power in finite samples. If the DF-GLS test cannot reject the null of nonstationary, one can implement the Zivot and Andrews (ZA) [65] test that allows for series to have a break at an unknown point in time. The choice of the deterministic component used in the test is determined based on the results of Akaike and Bayesian information criteria on two separate specifications, one with intercept only and the other one with intercept and linear trend, and secondly by visual inception of the series (Figure A1. ). The choice of the appropriate lag length is based on modified Akaike information criterion [66].

Since there is evidence of the variables being integrated of order I(1), and of cointegration among them (Section 6), this section focuses on cointegrating Vector Autoregression (VAR) as econometric methodology. This implies implementing a cointegration analysis using a VAR approach [67, 68], and estimate a Vector Error Correction (VECM) model of order $p$, where all variables are treated as endogenous: 
[Type here]

$$
\Delta x_{t}=\Gamma_{0}+\Pi x_{t-1}+\sum_{i=1}^{p} \Gamma_{i} X_{t-i}
$$

where $x_{t}$ is a 6 x 1 vector containing the logarithms of employment, GVA, and electricity generated by 1) conventional thermal, 2) CCGT, 3) nuclear and 4) renewable technologies, $\Pi$ and $\Gamma_{i}$ are $6 \times 6$ coefficient matrices and $\Gamma_{0}$ contains the deterministic terms. The trace and the maximum eigenvalue tests are employed to explore the appropriate number of cointegrating vectors. Regarding the deterministic terms in the cointegrating vectors, the choice of whether or not to include a linear trend is based on estimation of a model with intercept only and one with intercept and trend (following [69]. Once the long-term relationship between employment, output and electricity supply is identified ${ }^{9}$, one can compute the long-term response of employment to a positive shock in the electricity supply of each type of power generation technology using IRF analysis. The IRF describes the effect of a positive permanent shock on electricity supply at time $t$ on employment from time $t$ to $t+n$. In this way one can examine the response of employment to a $1 \mathrm{GWh}$ increase, independently taking place in each electricity production technology. As this is a reduced form model, the generalised IRF [71] is employed because it is invariant to the ordering of the variables in the VAR and "fully takes into account the historical patterns of the correlation observed amongst the different shocks" [72, 73].

\section{Data}

The dataset includes six variables, namely a) number of jobs, b) GVA, and electricity supply generated by c) conventional thermal, d) CCGT, e) nuclear and f) renewable technologies at an annual frequency from 1990 to $2016^{10}$. More precisely:

- Employment, or to be more precise number of jobs in the MPP firms, is measured by the number of "workforce jobs" on the UK national level. Workforce jobs are sourced from employer surveys like the Office for National Statistics (ONS) Labour Force Survey [74] on a quarterly basis from which yearly averages are computed. Although both full-time and part-time jobs are measured by workforce jobs, there is no distinct classification for the two types of jobs. Similarly, there is no information about the skill level of the employees. The lowest level of aggregation for which workforce jobs data are available in terms of SIC industrial classification is related to the "D" industrial sector which incorporates all MPPs firms and more generally firms related to "electricity, gas, steam and air conditioning".

\footnotetext{
${ }^{9}$ Results from the cointegration testing, discussed below in Section 6, preclude us from using the bound testing approach of Pesaran et al. [70], as this can be implemented only in the case on one cointegrating vector.

${ }^{10}$ Although energy supply data are currently available till 2018, 2017 and 2018 observations for GVA are currently reported only as provisional estimates and therefore subject to further changes. For this reason, this study used data up to 2016, the most recent year for which final GVA annual figures for the UK power sector are available.
} 
[Type here]

- Data on GVA related to the "D" industrial sector are published in annual figures by the ONS [75] and expressed in terms of 2010 prices (measured in million pounds). GVA measures the national level of economic activity or output of the related industrial sector.

- Electricity supply is equal to the total annual level of electricity supplied to end users in the UK generated by MPPs and it is reported separately for each type of energy generation technology. Electricity supply data for conventional thermal, CCGT, nuclear and renewable technologies, respectively, is obtained from DUKES that provide the longest time series on UK electricity supply measured in GWhs on an annual basis.

All data are converted into logarithms and thus estimated coefficients represent the elasticities of the variables.

\section{Results}

The results from unit root testing (Table A1) indicate that all variables are of order I(1) ${ }^{11}$. As the DFGLS unit root test ${ }^{12}$ indicates that only 3 of the 6 variables are I(1) (Table A1), namely employment, GVA and renewable electricity supply. Therefore, the remaining variables (conventional thermal, CCGT and nuclear electricity supply) are assessed by implementing the ZA test that allows for an unknown break in the series, a choice validated by the graphical visualisation of the series (Figure A1) ${ }^{13}$. The results of the ZA test confirm the existence of breaks and the fact that conventional thermal, CCGT and nuclear electricity supply are I(1) allows us to proceed with the VECM methodology. As the cointegration tests indicate the existence of four cointegrating vectors in the estimated system (Table A2) $)^{1415}$, the specified restrictions in the cointegrating vectors are based on both economic theory, i.e. the scale effect between output and employment represented in the first cointegrating vector $\beta_{l}$, and the historical relationships between the four electricity production technologies discussed in Section 3 in the three remaining cointegrating vectors. Vector $\beta_{2}$ is used to capture the substitution between conventional thermal and CCGT technologies, $\beta_{3}$ the substitution between conventional thermal and nuclear technologies and $\beta_{4}$ to capture the substitution between nuclear and renewable electricity plants.

\footnotetext{
11 This means that variables are non-stationary time-series.

12 This is a unit root test where the null hypothesis of non-stationarity is rejected when the test statistic is larger (in absolute values) than the critical value [64].

${ }^{13}$ This is a unit root test with structural breaks where the null hypothesis of non-stationarity is rejected in favour of the break-stationary alternative when the test statistic is larger (in absolute values) than the critical value [65]. The ZA test indicates the existence of a break in the series of conventional thermal, CCGT and nuclear electricity supply at the year 2013, 1995 and 2006, respectively, which can also be confirmed by visual inception of the abovementioned series in Figure A1.

${ }^{14}$ The cointegration test is a procedure that tests for the existence of $r$ cointegrating vectors among $k \mathrm{I}(1)$ series, where the null hypothesis of no cointegration is rejected in favour to the cointegration alternative when the $P$ value of the Likelihood Ratio (LR) test is lower than 0.05.

15 The cointegration tests have also been performed without incorporating the trend term and no significant difference was found.
} 
[Type here]

The resulting long-run component of a VECM including a trend in all cointegrating vectors turns out to be stable and with coefficients having reasonable signs and values (VECM 1 - Table 1). The cointegrating vector capturing the scale effect indicates the existence of a positive long-term coefficient equal to $0.96^{16}$ for the relationship between output and employment. When it comes to relationship between different electricity generation technologies, long-term coefficients are all negative as one would expect, with the long-term coefficient of CCGT $\left(\beta_{2}\right)$ taking the value of -0.31 , that of nuclear $\left(\beta_{3}\right)$ -1.36 and the coefficient capturing the substitution between nuclear and renewables $\left(\beta_{4}\right)$ being equal to -0.22 . The trend in $\beta_{1}$ is positive and equal to 0.35 while the trend in $\beta_{2}, \beta_{3}$ and $\beta_{4}$ is negative with values equal to $-0.12,-0.89$ and -1.02 , respectively. The unexpectedly high values (in absolute terms) of the trend in $\beta_{3}$ and $\beta_{4}$ vectors raise some initial concerns on the indication of four cointegrating vectors from the tests.

Table 1. Cointegrating vectors $\beta$ from specifications VECM 1 and VECM 2

\begin{tabular}{|c|c|c|c|c|c|c|c|c|}
\hline \multicolumn{9}{|c|}{ VECM 1} \\
\hline & Jobs & GVA & Conventional & $\underset{T}{\text { CCG }}$ & Nuclear & Renewables & Trend & Constant \\
\hline$\beta_{1}$ & 1 & -0.96 & & & & & -0.35 & 2.80 \\
\hline$\beta_{2}$ & & & 1 & 0.31 & & & 0.89 & -28.27 \\
\hline$\beta_{3}$ & & & 1 & & 1.36 & & -0.12 & -25.34 \\
\hline$\beta_{4}$ & & & & & 1 & 0.22 & -1.02 & 1.58 \\
\hline \multicolumn{9}{|c|}{ VECM 2} \\
\hline & Jobs & GVA & Conventional & $\underset{T}{\mathbf{C C G}}$ & Nuclear & Renewables & Trend & Constant \\
\hline$\beta_{1}$ & 1 & -1.06 & & & & & 0.06 & -2.32 \\
\hline$\beta_{2}$ & & & 1 & 0.46 & 0.76 & 0.30 & -0.001 & -28.25 \\
\hline
\end{tabular}

The statistical significance of the coefficients in the four cointegrating vectors is assessed with the use of the Likelihood Ratio (LR) test (Table 2) where a $P$-value lower than 0.05 indicates that the coefficient is statistically significant. The long-term coefficients are all strongly statistically significant, while the trend coefficient of $\beta_{1}$ vector is statistically significant only at $5 \%$ significance level and that in $\beta_{4}$ at $10 \%$ significance level. The validity of VECM 1 in Table 2 is also checked by implementing the Lagrange Multiplier (LM) test for serial correlation in the residuals and the White test for heteroskedasticity. The null hypothesis of serial correlation and homoscedasticity in the LM and White test, respectively, can be rejected when the $P$-value is lower than 0.05 . Table 3 reveals that the cointegrating VAR has homoscedastic residuals, while the null of no serial autocorrelation is rejected at $5 \%$ significance level in the case of LM test. To further test the validity of a model with four cointegrating relationships, two slightly modified specifications (VECM 1A and VECM 1B - Table A3)

\footnotetext{
16 Vector coefficients in Table 1 are presented in their matrix format. The reported coefficients in the text have opposite signs to those presented in the table, as it is customary in the field.
} 
[Type here]

are estimated where the trend coefficients in $\beta_{2}$ and $\beta_{3}$ are imposed to be zero, therefore enforcing the results from the LR tests in Table 2. One can see that in both VECM 1A and VECM 1B specifications, the exclusion of only one trend coefficient in each of the models has a considerable impact on the value of the long-term coefficients. The remaining trend coefficients in VECM 1A and VECM 1B have in most cases different signs and markedly different values from those for VECM 1 in Table 1, although they remain statistically significant (Table A4). The residuals in the alternative specifications VECM 1A and VECM 1B remain non-heteroskedastic similar to VECM 1, while they become non-serially correlated in VECM 1A (Table A5). Most importantly, both specifications VECM 1A and VECM 1B are not stable as they have one root out of the unit root circle, a pattern also observed for any alternative specification examined except for VECM 1 specification.

Table 2. $P$-values of the Likelihood Ratio (LR) tests for the coefficients in the cointegrating vectors in Table 1

\begin{tabular}{lccccccccc}
\hline & GV & \multirow{2}{*}{ CCGT } & NUC & REN & $\begin{array}{c}\text { Trend } \\
\beta_{1}\end{array}$ & $\begin{array}{c}\text { Trend } \\
\beta_{2}\end{array}$ & $\begin{array}{c}\text { Trend } \\
\beta_{3}\end{array}$ & $\begin{array}{c}\text { Trend } \\
\beta_{4}\end{array}$ & $\begin{array}{c}\text { All } \\
\text { trends }\end{array}$ \\
\hline VECM 1 & 0.00 & 0.00 & 0.00 & 0.00 & 0.04 & 0.31 & 0.15 & 0.07 & 0.00 \\
VECM 2 & 0.00 & 0.00 & 0.00 & 0.00 & 0.00 & 0.86 & & & 0.00 \\
\hline \hline
\end{tabular}

The fact that restricting one coefficient in VECM 1, based on indications from LR tests, implies considerable instability in the values of the other long-term coefficients, changes in their signs and ultimately explosive behaviour is taken as an indication that four cointegrating vectors in the system are a spurious result from cointegration testing. Therefore, VECM 1 is re-estimated with only two vectors, by assuming that $\beta_{1}$ captures the scale effect between employment and GVA, as before, and $\beta_{2}$ capturing the substitution effect between conventional thermal on one side, i.e. historically the main electricity generation technology used in the $\mathrm{UK}^{17}$, and CCGT, nuclear and renewables on the other side.

Table 3. Diagnostic tests for the residuals of the VECMs cointegrating vectors in Table 1

\begin{tabular}{lllc}
\hline & Lags & Serial correlation & Heteroskedasticity \\
\hline VECM 1 & 1 & 0.04 & 0.31 \\
VECM 2 & 1 & 0.17 & 0.40 \\
\hline \hline
\end{tabular}

The resulting specification (VECM 2 - Table 3) is stable and has coefficients in the cointegrating vectors of the same sign and value similar to those in the model with four cointegrating vectors (VECM 1). More specifically, the scale effect between employment and GVA remains positive with value equal to 1.06 (Table 1) which is fairly similar to the 0.96 value in VECM 1. Concerning the substitution effect, the coefficients for CCGT and renewables $(-0.46$ and -0.30 , respectively) are also close to those in VECM 1 . The only exception is the long-term coefficient of nuclear electricity which is equal to -0.76 ,

${ }^{17}$ Conventional thermal technologies have generated the largest amount of electricity supply in relation to independently each one of the other electricity generation technologies throughout the whole timespan with the exception of the years 2007, 2008 and 2016 (Figure 1). 
[Type here]

i.e. half the value of the coefficient in VECM 1. The trend coefficient in $\beta_{1}$ is equal to -0.06 while that in $\beta_{2}$ is almost equal to zero (0.001). The coefficients in the two cointegrating vectors are strongly significant - LR test in Table 2 - with only exception the trend coefficient in $\beta_{2}$. The validity of VECM 2 specification is supported by the failure to detect heteroskedasticity and serial correlation in the residuals (Table 3). Finally, the validity of the assumption of two cointegrating vectors is examined by assessing its robustness and estimating an alternative specification of VECM 2 where the nonstatistically trend term in the $\beta_{2}$ is dropped from the model. The results in Table A3 indicate that this change leaves all long-term coefficients in both vectors virtually unaffected so that their values and sign are almost identical to those in VECM 2 (Table 1). The $\beta$ coefficients in VECM 2A are strongly statistically significant (Table A4) while the diagnostic tests fail to detect heteroskedasticity and serial correlation in the residuals (Table A5). The stability of the system is not affected by this restriction, as VECM 2A turns out to be stable with four unit roots.

The last step involves the implementation of a $1 \mathrm{GWh}$ shock on each type of technology, separately, and the assessment of the resulting impact on employment for a time horizon of twenty years starting from year one - when shock occurs. Results indicate that employment responds negatively to a $1 \mathrm{GWh}$ permanent increase in annual conventional thermal electricity supply (Figure 2(a)) reaching the value of -0.3 in the long-term. This is a counterintuitive result that can be attributed to the fact that the most recent conventional thermal plant built in the UK predates the start of the sample and that production of electricity from coal plants has largely been decreasing since 1990. In other words, it is unlikely that moderate increase in generation would change expectations of generators on the decreasing share of this technology. In panel (b), one can observe that the employment effects of a shock in conventional thermal and CCGT technologies seem to have roughly symmetrically opposite shapes although the employment effect to a shock in conventional thermal is lower in absolute value compared to the impact of a shock to electricity produced from CCGT. This finding seems to reflect the considerable pattern of substitution observed in Figure 1(a). One can also observe that the impact of an increase in CCGT production builds up across time after it takes place and results in an even higher employment effect in the following 4 years where employment reaches its peak value of 0.4 jobs. In the case of a shock in nuclear supply, employment effect reaches a value of 0.5 jobs in the long-term. However, contrary to the impact of CCGT, the size of the impact decreases across time from an initial impact of 0.7. Finally, regarding the employment effect to a shock in renewable electricity, Figure 2(d) indicates that the immediate impact of 1 job reaches the peak of 4.7 jobs after 6 years and eventually stabilises near 3.5 jobs in the case of renewable electricity. It is interesting to notice that the impact of an increase in renewable electricity across time reflects the overall increasing trend observed in Figure 1(b), perhaps incorporating expectation on future increases. 


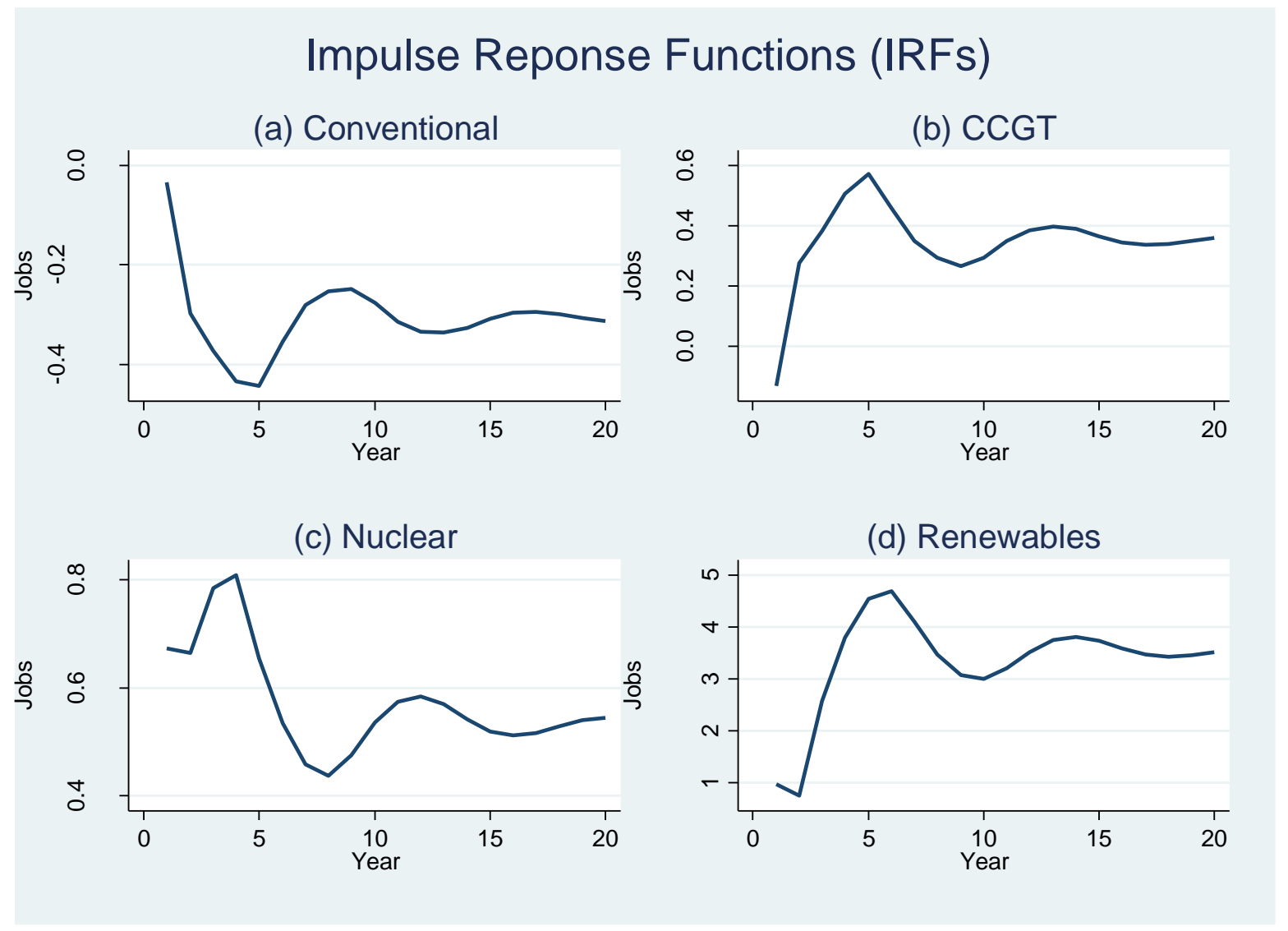

Figure 2. Impulse response functions (IRFs) for VECM 2 in Table 1. The graphs reveal the employment effect of a $1 \mathrm{GWh}$ permanent increase in electricity supply for each type of power generation technology.

\section{Discussion}

Starting with the scale effect, Table 1 confirms a positive relationship between GVA and employment, a result supported by [76] and in general by the extensive literature on the causal relationship between electricity use and economic growth [77]. The long-term elasticity of GVA takes the values 0.96 and 1.06 in the case of VECM 1 and VECM 2, respectively, hinting at a positive one-to-one relationship between output and employment. Regarding the relationship between different types of electricity, findings indicate that CCGT, nuclear and renewables are all substitutes of conventional thermal. As there is sufficient evidence to conclude that the indication of four cointegrating vectors is likely to be spurious, the focus is placed on the results produced by VECM 2 (Table 1) where two cointegrating vectors are assumed. CCGT electricity is a long-term substitute of conventional thermal electricity, with elasticity equal to -0.46 , a result supported by the literature related to interfuel substitution in the power industry [78]. Results further indicate that electricity generated by both nuclear and renewable technologies is a substitute of electricity generated by conventional thermal processes with elasticity equal to -0.76 and -0.30 , respectively. 
[Type here]

As mentioned in Section 2, there is a certain debate on whether jobs created by the deployment of renewable technologies can be sustainable in the long-term period. After examining the historical relationship between employment and electricity supply in the UK, findings indicates (Figure 2) that a permanent $1 \mathrm{GWh}$ increase in annual electricity supply generated by renewables creates 4.7 new jobs in the short-term period while 3.5 jobs in the long-term. Thus, $3 / 4$ of the jobs created by the deployment of renewable technologies are sustainable in the long run. Regarding nuclear electricity, a $1 \mathrm{GWh}$ increase creates 0.81 jobs in the short-term -6 times lower than those created by an equally sized increase in renewable electricity - while in the long-term employment stabilises at 0.54 jobs, i.e. 2/3 of the created jobs are sustainable in the long-run. Thus, the employment effect of nuclear electricity is not only much smaller in absolute terms than that of renewables but also less sustainable. When it comes to CCGT, the short-term employment effect is 0.57 jobs -8 times lower to that created by an equal sized increase in renewable electricity - while the long-term effect is 0.36 jobs. The fact that capacity utilization is normally lower for renewable electricity technologies compared to other technologies might have a role in explaining the higher employment impact of renewables, as a higher level of capacity needs to be built and maintained, compared to other technologies, in order to produced a given amount of electricity.

The similarity between this study's results and those estimated by [79] that use an IO model for Japan can be interpreted as evidence of robustness of the proposed approach. [79] find that the potential for job creation over the life cycle of different renewable technologies is estimated to range between 1.04 and 5.04 person-years per GWh. Older studies find similar but lower in magnitude effect for countries such as Brazil and Greece. [43] find that the total employment effect for Brazil is equal to 1.09 personsyears per GWh while [31] find that total employment effect for Greece ranges between 0.26 to 1.50 .

\subsection{Employment effect of UK decarbonisation scenarios for 2030}

From a policy perspective, and as a way of testing the methodology, one can investigate the potential future employment effect from a set of scenarios for electricity generation in 2030, produced by the UK Times (UKTM) model [80], by using the estimated long-run employment effect (Figure 2). The "Energy island" scenario is used as a counterfactual as it is the only one to assume that conventional thermal technologies will continue to be used until 2030. Table $4{ }^{18}$ reveals that "Low carbon (no Bioenergy with Carbon Capture Storage (BECCS))" and "Low carbon" are the only scenarios in which there is positive employment effect related to CCGT technologies equal to the creation of about 15,000 and 4,500 jobs, respectively. The only case of nuclear technologies have a positive employment effect equal to about

\footnotetext{
${ }^{18}$ Conventional thermal is not incorporated in Table 4 as the last coal plant has been commissioned in 1987 and since then UK power sector has been significantly reduced its reliance to conventional technologies.
} 
[Type here]

19,000 jobs is under the counterfactual in which $43 \%$ of total electricity supply is generated by nuclear. ${ }^{19}$ Renewable technologies are expected to create from a minimum of about 16,000 jobs to a maximum of about 186,000 under the "Low carbon (no BECCS)" and "Low carbon (no Carbon Capture Storage (CCS))" scenarios, respectively ${ }^{20}$. The key role of renewables in generating a significant number of jobs in the long-run is the reason why employment effect in the "Low carbon" scenario is substantially higher than the impact in the "Low carbon (no CCS)" as in the former negative emissions ${ }^{21}$ are delivered through CCS technologies.

Table 4. Employment effect for the UK Times (UKTM) model energy security scenarios [80]

\begin{tabular}{|l|c|c|c|c|}
\hline \multicolumn{1}{|c|}{ Scenario } & CCGT & Nuclear & Renewables & $\begin{array}{c}\text { Net } \\
\text { employment }\end{array}$ \\
\hline 1) Energy island & $-21,492$ & 19,303 & $-10,219$ & $-12,408$ \\
\hline 2) Slow decarbonisation & $-9,278$ & $-19,089$ & 60,034 & 31,668 \\
\hline 3) Low carbon & 4,499 & $-19,089$ & 53,549 & 38,960 \\
\hline 4) Low carbon (no CCS) & $-32,931$ & 0 & 185,594 & 152,539 \\
\hline 5) Low carbon (no BECCS) & 14,956 & $-19,089$ & 16,124 & 11,992 \\
\hline 6) Technology optimism & $-17,886$ & $-19,089$ & 75,136 & 38,162 \\
\hline
\end{tabular}

In contrast to the counterfactual in which there is negative net employment effect, all scenarios generate positive net employment effect which takes the minimum value of about 12,000 and maximum of about 152,500 jobs under the "Low carbon (no BECCS)" and "Low carbon (no CCS)" scenarios, respectively. The rest of the scenarios indicate that net employment in the long-term is expected to vary between about 31,000 to 39,000 jobs. ${ }^{22}$ Overall, results indicate that further support of policies supporting the deployment of renewables in the UK (e.g. CfD) can boost employment significantly in the power sector.

\section{Conclusions}

This article proposes a transparent and easily replicable methodology to estimate the employment effect of electricity generation technologies by using aggregated data on economic activity and employment in the power sector, and amount of electricity produced by different technologies. It analyses the UK power sector, using annual data from 1990 to 2016, although this approach can be easily applied to other countries. Results indicate renewable electricity creates about six times the number of jobs created

\footnotetext{
19 "Low carbon (no CCS)" scenario assumes that nuclear technologies will generate in 2030 the same amount of electricity as in 2016. This leads to no employment effect. The rest of the scenarios share the same assumption about nuclear electricity in 2030, which results in the same negative employment effect equal to $-19,089$ (Table 4).

${ }^{20}$ The "Low carbon (no BECCS)" scenario is the most conservative regarding renewable electricity as only $29 \%$ of the electricity is generated by renewables while the "Low carbon (no CCS)" assumes that $64 \%$ is generated by renewables and overwhelmingly by wind turbines. The rest of the scenarios, excluding "Energy island", assume that on average $48 \%$ of the electricity is generated by renewables.

${ }^{21}$ The best scenario in terms of $\mathrm{CO}_{2}$ emissions reduction is the "Low carbon" with negative emissions predicted while the second best is "Low carbon (no CCS)" [80]. The worst performance comes under the counterfactual "Energy island".

${ }^{22}$ Although we are aware of potential limitations due the implicit assumption of linearity in the effects, the plausibility of the results presented in Table 4 indicates the robustness of the suggested approach.
} 
[Type here]

by an equally sized increase in nuclear generation. The similarity of this study's findings with existing IO employment effect estimates indicates the robustness of the proposed approach. It also indicates that although simple, this approach is equivalently powerful to complex methods such as IO or CGE models.

The estimated long-run employment effect is applied to a set of scenarios for UK electricity generation in 2030 produced by the UKTM model [80] so as to analyse the employment implications of those scenarios. Bearing in mind recent reduction in the cost of solar generation technology and the fact that the UK has the largest global capacity in offshore wind energy [82], it becomes evident that renewables can have a considerable positive long-term employment effect. It is crucial that policymakers incentivise and support the deployment of renewable electricity technologies as this study provides robust evidence of their employment impact in scenarios aimed at progressing the decarbonisation of the UK economy. Nevertheless, it has to be taken into account that findings focus on the power sector and therefore this study does not identify potential indirect job employment effects (e.g. manufacturing sector). Since the focus is on the aggregate level of the UK economy, the model cannot control for structural changes on the micro level of the labour market such as changes in wages and opportunity costs, changes in competitiveness due to demographic factors and potential supply constraints.

Future studies should try to address the limitation of the current implementation and develop reducedform models able to identify the broader employment effect of the deployment of renewables technologies in sectors such as manufacturing, construction or services. In particular, it would be helpful if technological change influencing the composition of renewable generation, e.g. a further shift toward solar PV, or the labour intensity of the renewable technologies could be incorporated in the model, perhaps through a non-observable factor approach. Collection of data for smaller geographical areas would enable the estimation of "local" models, therefore taking into account the fact that the employment effect of renewables might be influenced by the location of the technology on the grid or their distance from the shore, in case of offshore wind. Similarly, collection of data for periods shorter than one year, such as quarter, would enable the analysis of seasonal effects in the employment which could be expected for technologies affected by rough wintery conditions, such as offshore wind. On the other hand, it is also possible that the schedule of regular maintenance in the summer period, could make up for the increase in unforeseen repairs likely to be observed in the winter season. Based on purely statistical considerations, access to more granular data would increase the size of the sample available for empirical analysis, therefore probably increasing the confidence in the obtained estimates of the employment effects discussed here, while reducing loss of information related to heterogeneity of the effect across time and space.

It would also help if future studies could implement this approach, perhaps while tackling some of the limitations pointed above, to other countries to increase the empirical evidence base on the employment effect but also to explore the extent to which the effect varies across countries. It is reasonable to expect 
[Type here]

differences in the employment effect of renewables across countries due to: i) differences in the composition of the renewable sector; ii) in the phase of renewable deployment, i.e. some countries are at an advanced stage, while others less so); iii) in the share of renewable electricity production which is exported; and finally iv) in terms of industrial and labour policy. One would potentially expect similar results for countries that have followed similar trajectories in investing in renewable resources during the last two decades such as Denmark and Germany [81]. In fact, both countries along with the UK have been leading world's offshore wind installed capacity in 2016 [82, 83]. Thus, it would be interesting to replicate the model for those countries and compare employment effects. On the other hand, the proposed methodology might not be the most helpful for countries such as Greece and Poland that have historically over-relied on fossil fuels (mainly lignite) to generate energy by centrally controlled conventional thermal plants $[84,85,86]$, due to the fact that historical deployment of renewable technologies is limited. It is also very likely that the results in these two countries would likely be very different from those obtained for the UK not only because they are at an earlier stage of deployment but also because the labour market in the UK is much more flexible.

\section{Acknowledgements}

We would like to thank Paul Dodds and Jim Watson for granting access to the results of the scenarios produced by the UKTM model discussed in Watson et al. [80], and Vincenzo De Lipsis, Paul Dodds, Will McDowall, Jim Watson, Philip Ulrich and the participants of $16^{\text {th }}$ International Association for Energy Economics (IAEE) European Conference for useful comments on previous versions of the paper. Finally, we are grateful to the editor and five anonymous reviewers for constructive comments and feedback that substantially improved the contents and the presentation of this article. This research has been supported by the Natural Environment Research Council (NE/M019799/1) and by the UK Energy Research Centre (Grant Number: EP/L024756/1).

\section{Research data and syntax for this article}

All data and syntax used in this article can be accessed online in the OSF repository at https://osf.io/XS36M.

\section{References}

[1] Pachauri RK, Meyer LA. Climate change 2014 synthesis report. Contribution of working groups I, II, and III to the fifth assessment report of the Intergovernmental Panel on Climate Change; 2014. 
[Type here]

[2] Renewable energy jobs: status, prospects and policies. International Renewable Energy Agency; $2011 . \quad$ https://www.irena.org/Imedia/Files/IRENA/Agency/Publication/2012/RenewableEnergyJobs.pdf.

[3] Meyer I, Sommer M. Employment effects of renewable energy supply: a meta analysis. Policy $\begin{array}{lllll}\text { paper } & \text { no } & 12 & \text { WIFO; }\end{array}$ https://www.wifo.ac.at/bibliothek/archiv/36286/WWWforEurope PP 12.pdf.

[4] Renewable energy and job: annual review 2019. International Renewable Energy Agency; 2019. https://www.irena.org/publications/2019/Jun/Renewable-Energy-and-Jobs-Annual-Review2019.

[5] Cameron L, Zwaan B. Employment factors for wind and solar energy technologies: a literature review. Renewable and Sustainable Energy Reviews 2015;45:160-172.

[6] State of the energy market. Office of Gas and Electricity Markets; 2018. https://www.ofgem.gov.uk/publications-and-updates/state-energy-market-2018.

[7] Bowen A, Kuralbayeva K. Looking for green jobs: the impact of green growth on employment. Grantham Research Institute on Climate Change and Environment; Policy Brief; March 2015. http://www.lse.ac.uk/GranthamInstitute/wp-content/uploads/2015/03/Looking-for-green-jobs theimpact-of-green-growth-on-employment.pdf.

[8] McNeill J, Williams J. The employment effects of sustainable development policies. Ecological Economics 2007; 64:216-223.

[9] Spalding-Fecher R, Narayan Achanta A, Erickson P, Haites E, Lazarus M, Pahuja N, Pandey $\mathrm{N}$, Seres S, Tewari R. Assessing the impact of the clean development mechanism. CDM Policy Dialogue;2012. https://www.sei.org/publications/assessing-the-impact-of-the-clean-developmentmechanism/.

[10] Sheikh N, Kocaoglu D, Lutzenhiser. Social and political impacts of renewable energy: literature review. Technological Forecasting and Social Change 2016;108:102-110.

[11] Allan G, Ross A. The characteristics of energy employment in a system-wide context. Energy Economics 2019;81:238-258.

[12] Baer P, Brown M, Kim G. The job generation impacts of expanding industrial cogeneration. Ecological Economics 2015;110:141-153.

[13] Markari M, Belegri-Roboli A, Michaelides P, Mirasgedis S, Lalas D. The impact of clean energy investments on the Greek economy: an input-output analysis (2010-2020). Energy Policy 2013;57:263-275.

[14] Oliveira C, Coelho D, da Silva P, Antunes C. How many jobs can the RES-E sectors generate in the Portuguese context? Renewable and Sustainable Energy Reviews 2013;21:444-455.

[15] Wang C, Weishi Z, Cai W, Xie X. Employment impacts of CMD projects in China's power sector. Energy Policy 2013;59:481-491. 
[Type here]

[16] Lambert R, Silva P. The challenges of determining the employment effects of renewable energy. Renewable and Sustainable Energy Reviews 2012;16:4667-4674.

[17] Bohlmann H, Horridge J, Inglesi-Lotz R, Roos E, Stander L. Regional employment and economic growth effects of south Africa's transition to low-carbon energy supply mix. Energy Policy 2019;128:830-837.

[18] Chatri F, Yahoo M, Othman J. The economic effects of renewable energy expansion in the electricity sector: a CGE analysis for Malaysia. Renewable and Sustainable Energy Reviews 2018;95:203-216.

[19] Mu Y, Wenjia C, Evans S, Wang C, Rolan-Host D. Employment impacts of renewable energy policies in china: a decomposition analysis based on a CGE modelling framework. Applied Energy 2018;210:256-267.

[20] Kabayo J, Marques P, Carcia R, F Freire. Life-cycle sustainability assessment of key electricity generation system in Portugal. Energy 2019;176:131-142.

[21] Fanning T, Jones C, Munday M. The regional employment returns from wave and tidal energy: a Welsh analysis. Energy Economics 2014;76:958-966.

[22] Zwaan B, Cameron L, Kober. T. Potential for renewable energy jobs in the Middle East. Energy Policy 2013;60:296-304.

[23] Wei M, Patadia S, Kammen D. Putting renewables and energy efficiency to work: how many jobs can the clean energy industry generate in the US? Energy Policy 2010;38:919-931.

[24] Blanco M, Rodriquez G. Direct employment in the wind energy sector: an EU study. Energy Policy 2009;37:2847-2857.

[25] Stavropoulos S, Burger M. Modelling strategy and net employment effects of renewable energy and energy efficiency: a meta-regression. Energy Policy 2020;136:111047.

[26] Lutz C, Lehr U. Summary of the final report macroeconomic effects and distributional issues of energy transition. Study on behalf of the Federal Ministry for Economic Affairs and Energy. GWS; 2018. https://www.bmwi.de/Redaktion/EN/Publikationen/Studien/macroeconomic-effects-anddistributional-issues-of-energy-transition.pdf? _blob=publicationFile \&v=3.

[27] Lutz C, Flaute M, Lehr U, Wiebe K. Economic impacts of renewable power generation technologies and the role of endogenous technological changes. Open Journal of Applied Sciences 2015;5:696-704.

[28] Lutz C, Lehr U, Ulrich P. Economic evaluation of climate protection measures in Germany. International Journal of Energy Economics and Policy 2014;4:693-705.

[29] Lehr U, Nitsch J, Kratzat M, Lutz C, Edler D. Renewable energy and employment in Germany. Energy Policy 2008;36:108-117.

[30] Gkatsou S, Kounenou M, Papanagiotou P, Seremeti D, Georgakellos D. The impact of green energy on employment: a preliminary analysis. International Journal of Business and Social Science 2014;5:29-41. 
[Type here]

[31] Tourkolias C, Mirasgedis S. Quantification and monetization of employment benefits associated with renewable energy technologies in Greece. Renewable and Sustainable Energy Reviews 2011;15:2876-2886.

[32] Ciorba U, Pauli F and Menna P. Technical and economical analysis of an induced demand in the photovoltaic sector. Energy Policy 2004;32:949-960.

[33] Moreno B, López A. The effect of renewable energy on employment. The case of Asturias (Spain). Renewable and Sustainable Energy Reviews 2008;12:732-751.

[34] Green jobs for sustainable development: a case for Spain. International Labour Organisation; 2012. https://www.ilo.org/global/topics/green-jobs/publications/WCMS_186715/lang--en/index.htm.

[35] Çetin M, Eğrican N. Employment impacts of solar energy in Turkey. Energy Policy 2011;39:7184-7190.

[36] Topcu I, Ulenging F, Ozgur K, Isik M, Unver B, Ekici S. The valuation of electricity generation resources: the case of Turkey. Energy 2019;167:417-427.

[37] Kost C, Engelken M, Schlegl T. Value generation of future CSP projects in North Africa. Energy Policy 2012;46:88-99.

[38] Sohrab T, Karkoodi S, Roumi S. Estimation of the employment rate of Iranian solar power plants in the horizon of 2050. International Journal of Ambient Energy; 2019.

[39] Green Growth: The impact of wind energy in jobs in the economy. The European Wind Energy Association;

2012.

http://www.ewea.org/fileadmin/files/library/publications/reports/Green_Growth.pdf.

[40] Brown J, Pender J, Wiser R, Lantz E, Hoen, B. Ex post analysis of economic impacts from wind power development in US counties. Energy Economics 2012;34:1743-1754.

[41] Yi H. Clean energy policies and green jobs: an evaluation of green jobs in U.S. metropolitan areas. Energy Policy 2013;56:644-652.

[42] Gonçales S, Rodrigues T, Chagas A. The impact of wind power on the Brazilian labor market. Renewable and Sustainable Energy Reviews 2020;128:109887.

[43] Simas M, Pacca S. Assessing employment in renewable energy technologies: a case study for wind power in Brazil. Renewable and Sustainable Energy Reviews 2014;31:83-90.

[44] Caldés A, Varela M, Santamaría M, Sáez R. Economic impact of solar thermal electricity in Spain. Energy policy 2009;37:1628-1636.

[45] Osiolo H. Green energy and its impact on employment and economic growth. UNU-INRA Working Paper.19; 2016. https://collections.unu.edu/eserv/UNU:5928/WP Helen 15122016 UNUINRA.pdf.

[46] Hartley R, Medlock III K, Temzelides T, Zhang X. Local employment impact from competing energy sources: shale gas versus wind generation in Texas. Energy economics 2015;49:610-619. 
[Type here]

[47] Ek K, Persson L. Wind farms - where and how to place them? A choice experiment approach to measure consumer preferences for characteristics of wind farm establishments in Sweden. Ecological Economics 2014;105:193-203.

[48] Mori-Clement Y, Bednar-Friedl B. Do clean development mechanism projects generate local employment? Testing for sectoral effects across Brazilian Municipalities." Ecological Economics 2019; $157: 47-60$.

[49] Blazejczak J, Braun F, Dietmar E, Schill W. Economic effects of renewable energy expansion: a model-based analysis for Germany. Renewable and Sustainable Energy Reviews 2014;40:1070-1080.

[50] Louie E, Pearce J. Retraining investment for U.S. transition from coal to solar photovoltaic employment. Energy Economics 2016;57:295-302.

[51] Cohen S, Caron J. The economic impacts of high wind penetration scenarios in the United States. Energy Economics 2018;76:558-573.

[52] Ferroukhi R, Lopez-Peña A, Kieffer G, Nagpal D, Hawila D, Khalid A, El-Katiri L, Vinci S, Fernandez A. Renewable energy benefits: measuring the economics. International Renewable Energy Agency; 2016. https://www.irena.org/publications/2016/Jan/Renewable-Energy-Benefits-Measuringthe-Economics.

[53] Thornley P, Rogers J, Huang Y. Quantification of employment from biomass power plants. Renewable Energy 2008;33:1922-1927.

[54] Rivers N. Renewable energy and unemployment: a general equilibrium analysis. Resource and Energy Economics 2013;35:467-485.

[55] Böhringer C, Keller A, van der Werf E. Are green hopes too rosy - employment and welfare impacts of renewable energy promotion. Energy Economics 2013;36:277-285.

[56] Apergis N, Salim R. Renewable energy consumption and unemployment: evidence from a sample of 80 countries and nonlinear estimates. Applied Economics 2015;46:5614-5633.

[57] Perriera Q, Quirion P. How shifting investment towards low-carbon sectors impacts employment: three determinants under scrutiny. Energy Economics 2018;75:464-483.

[58] Heavner B, Churchill S. Renewables work: job growth from renewable energy development in $\begin{array}{llll}\text { California. } & \text { CALPIGR } & \text { Charitable } & \text { Trust; }\end{array}$ https://cleanenergysolutions.org/fr/resources/renewables-work-job-growth-renewable-energydevelopment-california.

[59] Rutovitz J, Atherton A. Energy sector jobs to 2030: a global analysis. Institute for Sustainable Futures, UTS; 2009. https://opus.lib.uts.edu.au/bitstream/10453/35047/1/rutovitzatherton2009greenjobs.pdf.

[60] Liera E, Scarpellini A, Aranda A, Zabalza I. Forecasting job creation from renewable energy deployment through a value-chain approach. Renewable and Sustainable Energy Reviews 2013;21:262271. 
[Type here]

[61] Digest of UK energy statistics. Department for Business, Energy and Industrial Strategy; 2017. https://www.gov.uk/government/statistics/digest-of-uk-energy-statistics-dukes-2017-main-report.

[62] Bocse A, Gegenbauer C. UK's dash for gas: Implications for the role of natural gas in European power generation. Strategy paper 14, EUCERS; 2017. https://eucers.com/wpcontent/uploads/2019/03/strategy-paper-14.pdf.

[63] Panagiotidis T, Rutledge E. Oil and gas markets in the UK: evidence from a cointegrating approach. Energy Economics 2007;29:329-347.

[64] Elliott G, Rothenberg T, Stock J. Efficient tests for an autoregressive unit root. Econometrica 1996;64:813-836.

[65] Zivot E; Andrews K. Further evidence on the great crash, the oil price shock, and the unit root hypothesis. Journal of business and Economic Statistics 1992;10:251-270.

[66] Ng S, Perron S. LAG length and the construction of unit roots tests with good size and power. Econometrica 2001;69:1519-1554.

[67] Johansen S. Statistical analysis of cointegration vectors. Journal of Economic Dynamics and Control 1988;2-3:231-254.

[68] Johansen S. Estimation and hypothesis testing of cointegration vectors in Gaussian vector autoregressive models. Econometrica 1991;59:1551-1580.

[69] Johansen S. Determination of cointegration rank in the presence of a linear trend. Oxford Bulletin of Economics and Statistics 1992;54:383-397.

[70] Pesaran H, Yoncheol S, Smith R. Bounds testing approaches to the analysis of level relationships. Journal of Applied Econometrics 2001;16:289-326.

[71] Koop G, Pesaran H, Potter S. Impulse response analysis in nonlinear multivariate models." Journal of Econometrics 1996;74:119-147.

[72] Pesaran H, Shin Y. Generalized impulse response analysis in linear multivariate models. Economic Letters 1998;58:17-29.

[73] Pesaran H, Smith R. Structural analysis of cointegrating VARs. Journal of Economic Surveys 1998;12:471-505.

[74] UK labour market: July 2018. Office for National Statistics; 2018. https://www.ons.gov.uk/releases/uklabourmarketstatisticsjuly2018.

[75] A guide to the UK national accounts: march 2020. Office for national Statistics; 2020. https://www.ons.gov.uk/economy/nationalaccounts/uksectoraccounts/methodologies/aguidetotheuknat ionalaccountsmarch2020.

[76] Narayan P, Smyth R. Electricity consumption, employment and real income in Australia evidence from multivariate Granger causality tests. Energy Policy 2005;33:1109-116.

[77] Payne J. A survey of the electricity consumption-growth literature. Applied Energy 2010;87:723-731. 
[Type here]

[78] Gao J, Nelson R, Zhang L. Substitution in the electric power industry: an interregional comparison in the eastern US. Energy Economics 2013;40:316-325.

[79] Hondo H, Moriizumi Y. Employment creation potential of renewable power generation technologies: a life cycle approach. Renewable and Sustainable Energy Reviews 2017;79:128-136.

[80] Watson J, Ketsopoulou I, Dodds P, Chaudry M, Tindemans S, Woolf M. Strab G. The security of UK energy futures. London, UK Energy Research Centre; 2018. https://ukerc.rl.ac.uk/UCAT/PUBLICATIONS/UKERC Security of UK Energy Futures.pdf.

[81] Lipp J. Lessons for effective renewable electricity policy from Denmark, Germany and the United Kingdom. Energy Policy 2007;35:5841-5495.

[82] The clean growth strategy. Department for Business, Energy and Industrial Strategy; 2017. https://assets.publishing.service.gov.uk/government/uploads/system/uploads/attachment_data/file/700 496/clean-growth-strategy-correction-april-2018.pdfg.

[83] Global wind 2017 report. A snapshot of top wind markets in 2017: offshore wind. Global Wind Energy Council; 2017. https://gwec.net/wp-content/uploads/2018/04/offshore.pdf.

[84] The economics of Greek lignite plants: end of an era. The Green Tank; 2019. https://thegreentank.gr/en/2019/09/03/economics-lignite-greece en/.

[85] Greek energy market report 2019. Hellenic Association for Energy Economics; 2019. https://www.haee.gr/media/4858/haees-greek-energy-market-report-2019-upload-version.pdf.

[86] Widera M, Kasztelewicz Z, Ptak M. Lignite mining and electricity generation in Poland: the current state and future prospects. Energy Policy 2016;92:151-157. 
[Type here]

Appendix 


\section{[Type here]}

Table A1. Unit root test results for Major Power Producers (MPPs)

\begin{tabular}{|c|c|c|c|c|c|c|c|c|c|c|}
\hline & \multicolumn{3}{|c|}{ Logs } & \multicolumn{3}{c|}{ First differences } & \multicolumn{3}{c|}{ Logs } & \multicolumn{2}{c|}{ First differences } \\
\hline & $\begin{array}{c}\text { DF-GLS } \\
\text { test }\end{array}$ & lags & $\begin{array}{c}\text { Deterministic } \\
\text { components }\end{array}$ & DF-GLS test & lags & $\begin{array}{c}\text { Deterministic } \\
\text { components }\end{array}$ & ZA test & lags & ZA test & lags \\
\hline Jobs & -1.46 & 1 & Trend & $-3.91^{(*)}$ & 0 & Trend & & & \\
\hline GVA & -1.18 & 2 & Trend & $-6.43^{(* *)}$ & 0 & Trend & & & \\
\hline Conv. thermal & -1.43 & 0 & Trend & -1.49 & 2 & Trend & -1.86 & 2 & $-7.31^{(* *)}$ & 0 \\
\hline CCGT & -1.97 & 1 & Trend & -2.81 & 1 & Trend & -3.67 & 0 & $-4.59^{(*)}$ & 1 \\
\hline Nuclear & -2.27 & 0 & Trend & -1.85 & 3 & Trend & -3.45 & 3 & -10.19 & 0 \\
\hline Renewables & -1.57 & 0 & Trend & $-6.15^{(* *)}$ & 0 & Trend & & & & 0 \\
\hline
\end{tabular}

${ }^{(+)}{ }^{(*)}{ }^{(* *)}$ in the superscripts indicate significance of the test statistics of the unit root tests at $90 \%, 95 \%$ and $99 \%$ significance level, respectively. If the DFGLS test cannot prove sufficient evidence that the series is I(1), one has to implement the Zivot and Andrews test (ZA) that allows for a break at an unknown point in time. 
[Type here]

Table A2. Johansen test cointegration results

\begin{tabular}{|l|cc|cc|cc|cc|}
\hline & \multicolumn{4}{|c|}{ Trace } & \multicolumn{4}{c|}{ Max Eigenvalue } \\
\cline { 2 - 8 } & H0 & H1 & $\lambda_{\text {trace }}$ & $\boldsymbol{p}$-value & H0 & H1 & $\lambda_{\max }$ & $\boldsymbol{p}$-value \\
\hline \multirow{4}{*}{ MPPs } & $\mathrm{r}=0$ & $\mathrm{r} \geq 1$ & $0.973^{(* *)}$ & $(0.00)$ & $\mathrm{r}=0$ & $\mathrm{r}=1$ & $0.973^{(* *)}$ & $(0.00)$ \\
& $\mathrm{r} \leq 1$ & $\mathrm{r} \geq 2$ & $0.897^{(* *)}$ & $(0.00)$ & $\mathrm{r}=1$ & $\mathrm{r}=2$ & $0.897^{(* *)}$ & $(0.00)$ \\
& $\mathrm{r} \leq 2$ & $\mathrm{r} \geq 3$ & $0.827^{(* *)}$ & $(0.00)$ & $\mathrm{r}=2$ & $\mathrm{r}=3$ & $0.827^{(* *)}$ & $(0.00)$ \\
& $\mathrm{r} \leq 3$ & $\mathrm{r} \geq 4$ & $0.737^{(* *)}$ & $(0.00)$ & $\mathrm{r}=3$ & $\mathrm{r}=4$ & $0.737^{(* *)}$ & $(0.01)$ \\
& $\mathrm{r} \leq 4$ & $\mathrm{r} \geq 5$ & 0.507 & $(0.14)$ & $\mathrm{r}=4$ & $\mathrm{r}=5$ & 0.507 & $(0.11)$ \\
\hline
\end{tabular}

Results from the Trace and Max Eigenvalue cointegration tests. $\left.\left.{ }^{(+)}{ }^{(*)}\right)^{(* *}\right)$ in the superscripts indicate significance of the test statistics of the unit root tests at $90 \%, 95 \%$ and $99 \%$ significance level,

respectively.

Table A3. Cointegrating vectors $\beta$ from alternative VECM specifications to those presented in Table 1

\begin{tabular}{|c|c|c|c|c|c|c|c|c|}
\hline \multicolumn{9}{|c|}{ VECM 1A } \\
\hline & Jobs & GVA & Conv & $\begin{array}{c}\mathbf{C C G} \\
\mathbf{T}\end{array}$ & Nuclear & Renewables & Trend & Constant \\
\hline$\beta_{1}$ & 1 & -0.73 & & & & & 0.05 & -5.32 \\
\hline$\beta_{2}$ & & & 1 & 0.56 & & & & -18.17 \\
\hline$\beta_{3}$ & & & 1 & & 1.30 & & 0.03 & -26.90 \\
\hline$\beta_{4}$ & & & & & 1 & 0.64 & -0.02 & -16.80 \\
\hline \multicolumn{9}{|c|}{ VECM 1B } \\
\hline & Jobs & GVA & Conv & $\underset{\mathbf{T}}{\mathbf{C C G}}$ & Nuclear & Renewables & Trend & Constant \\
\hline$\beta_{1}$ & 1 & -1.03 & & & & & 0.21 & -4.76 \\
\hline$\beta_{2}$ & & & 1 & 0.35 & & & -0.30 & -11.38 \\
\hline$\beta_{3}$ & & & 1 & & 1.15 & & & -24.71 \\
\hline$\beta_{4}$ & & & & & 1 & 0.27 & 0.37 & -19.09 \\
\hline \multicolumn{9}{|c|}{ VECM 2A } \\
\hline & Jobs & GVA & Conv & $\underset{T}{\mathbf{C C G}}$ & Nuclear & Renewables & Trend & Constant \\
\hline$\beta_{1}$ & 1 & -1.06 & & & & & 0.06 & -2.27 \\
\hline$\beta_{2}$ & & & 1 & 0.44 & 0.77 & 0.28 & & -28.19 \\
\hline
\end{tabular}

Table A4. $P$-values of the Likelihood Ratio tests for the coefficients in the cointegrating vectors $\beta$ presented in Table A3

\begin{tabular}{cccccccccc}
\hline GVA & $\begin{array}{c}\text { CCG } \\
\mathbf{T}\end{array}$ & NUC & REN & $\begin{array}{c}\text { Trend } \\
\beta_{1}\end{array}$ & $\begin{array}{c}\text { Trend } \\
\beta_{2}\end{array}$ & $\begin{array}{c}\text { Trend } \\
\beta_{3}\end{array}$ & $\begin{array}{c}\text { Trend } \\
\beta_{4}\end{array}$ & $\begin{array}{c}\text { All } \\
\text { trends }\end{array}$ \\
\hline $\begin{array}{c}\text { VECM } \\
\mathbf{1 A}\end{array}$ & 0.00 & 0.00 & 0.00 & 0.00 & 0.01 & & 0.00 & 0.40 & 0.00 \\
$\begin{array}{c}\text { VECM } \\
\mathbf{1 B}\end{array}$ & 0.00 & 0.00 & 0.00 & 0.00 & 0.02 & 0.00 & & 0.00 & 0.00 \\
$\begin{array}{c}\text { VECM } \\
\text { 2A }\end{array}$ & 0.00 & 0.00 & 0.00 & 0.00 & 0.00 & & & & \\
\hline \hline
\end{tabular}


[Type here]

Table A5. Diagnostic tests for the residuals of the VECMs cointegrating vectors presented in Table A3

\begin{tabular}{lccc}
\hline & Lags & Serial correlation & Heteroskedasticity \\
\hline VECM 1A & 1 & 0.37 & 0.32 \\
VECM 1B & 1 & 0.03 & 0.32 \\
VECM 2A & 1 & 0.20 & 0.38 \\
\hline \hline
\end{tabular}
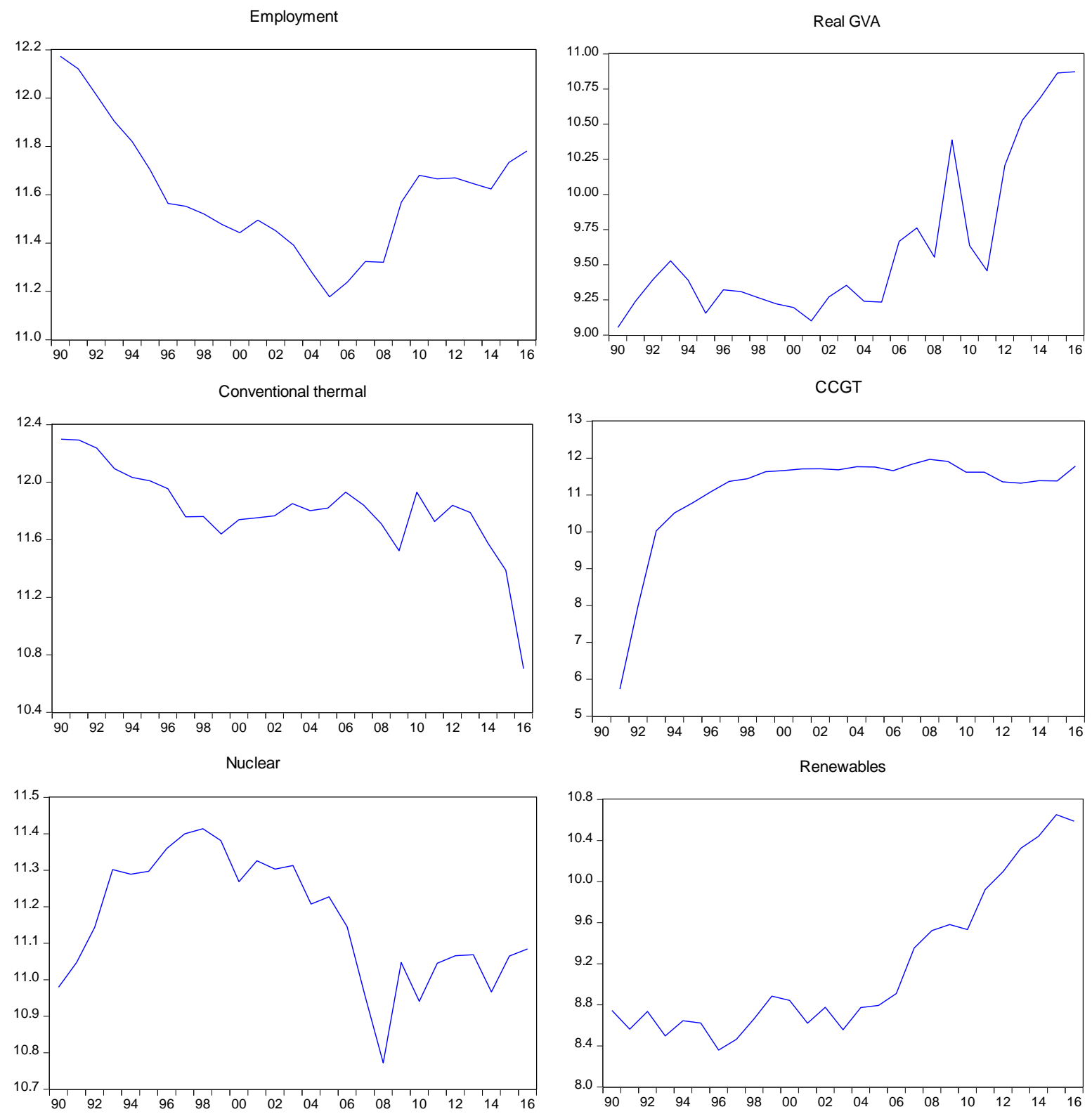

Figure A1. Variables employed in the empirical analysis. The graphs depict the time series for all variables expressed in logarithms 